\title{
Filósofos ante la muerte Una reflexión acerca de la vida y de la muerte
}

\author{
Carlos Alvarado de Piérola \\ Departamento Académico de Filosofía
}

Nuestras vidas son los ríos, que van a dar en la mar, que es el morir;

JoRge MANRIQUE

If 1 hecho de la muerte nos coloca ante una situación límite. Es, induda-

1. blemente, el acontecimiento más importante en nuestra vida. Y, aun cuando ha escrito La Rochefoucauld que " $\mathrm{ni}$ el sol ni la muerte pueden mirarse con fijeza",' esto no es tan cierto. No es imposible mirar de frente a la muerte, compañera inseparable de la vida. Es más, tal vez sea necesario hacerlo, para comprenderla y desentrañar las tinieblas que suelen envolverla. No importa que Spinoza nos haya dicho: "Un hombre libre en nada piensa menos que en la muerte, y su sabidurīaing èsuna meditaciön de la muerte, sino de la vida". ${ }^{2}$ La reflexión sobre la vida nosconduce, ineluctablemente, a reflexionar sobre la muerte. Cuando nos formulamos la interrogante ¿qué es la muerte? nos planteamos un problema que, con seguridad, se ha generado a partir de la pregunta ¿qué es la vida?

De hecho, ha sido éste uno de los problemas que más ha preocupado al espíritu humano. A través de su historia, el hombre no ha podido soslayar el tema de la muerte, aunque a veces, por razones comprensibles, hubiera deseado intentarlo; sin embargo, no ha podido evitar el enfrentarla, pues la muerte nos está permanentemente recordando su presencia. En consecuencia, es explicable que éste se haya convertido en un tema frecuentemente presente en las preocupaciones del hombre común, de la ciencia y sobre todo, de la filosofía.

\footnotetext{
' Apud Luis Bourdeau, El problema de la muerte, p. 1.

${ }^{2}$ Benedicto Spinoza, Ética, Prop. LXVII, parte 4a.
} 
Sobre esto último, conviene recordar lo que escribió Schopenhauer: "La muerte es el genio inspirado, la Musa de la filosofía... sin ella difícilmente se hubiera filosofado". ${ }^{3}$ Hay motivos para suponer, en consecuencia, que, ligado como está al problema de la vida, es uno de los más dignos problemas que pueden ocupar nuestras meditaciones.

De allí que los filósofos la han elegido como tema frecuente de sus creaciones. Platón dijo que la filosofía es una constante meditación sobre la muerte y Cicerón-definió a la filosofía como "meditatio mortis".

La biología moderna ha confirmado el hecho de que la muerte está ya an-ticipada en nuestra información genética. Ante semejante evidencia, resulta cu-rioso constatar que siempre se ha considerado a la muerte como algo ajeno a esa vida de que se ocupa la biología. Ahora sabemos que esto es un error, pues los genes que participan en la muerte celular aparecieron desde muy temprano y se conservan hasta hoy en día. Lo cual quiere decir que estamos programados para morir. ${ }^{4}$

La muerte es, pues, un hecho que debe interesarnos. Por supuesto, no bajo la forma de un interés morboso o de una obsesión patológica, sino como un objeto de reflexión. Sin embargo, el tema de la muerte es objeto de un deliberado ocultamiento, sobre todo en nuestra cultura occidental. Es más, a veces se llega a considerar hasta de mal gusto tratar el tema. Por este motivo, cuando ella llega, no estamos listosiparä enffentarla. 4 a matyoriade las personas no estamos preparados para enfrentar nuestrondestine. parasceptar la inminencia de nuestra propia muerte o, inclusive, la ajena. Es más, el hombre común busca eludir su sola mención como una forma de negarla; en ocasiones, hasta llega a experimentar con relación a ella un estado de terror muy cercano a lo patológico. ${ }^{5}$ Incluso la palabra "muerte" es deliberadamente evitada y, para evitar que hiera a los oídos, se le reemplaza con eufemismos. No se dice de alguien que "ha muerto", sino que "ha pasado a mejor vida", "ha cesado de existir", "nos ha dejado", etc. "Ya el 'pensar en la muerte' pasa públicamente por cobarde temor", nos va a decir el filósofo Martín Heidegger. ${ }^{6}$ Tan poderoso es este sentimiento de horror que Wilhelm Steckel escribió que todo temor es, en último término, un temor de la muerte. ${ }^{7}$

\footnotetext{
3 Arturo Schopenhauer, El amor, las mujeres y la muerte, p. 78.

- Cf. Marcelino Cerejeido y Fanny Blanck-Cerejeido, La muerte y sus ventajas.

3 Situación que es hábilmente explotada por quienes han creado la lucrativa industria cinematográfica del terror.

${ }^{6}$ Martín Heidegger, Ser y tiempo, p. 277.

'Apud John Hinton, Experiencias sobre el morir, p. 40.
} 
"A los más de los nuestros les asusta la muerte y se santiguan como si oyesen mencionar al diablo" escribió don Miguel de Montaigne en un ensayo acertadamente titulado "De cómo filosofar es aprender a morir". ${ }^{8} \mathrm{Y}$ agregó: "El fin de nuestra carrera es la muerte, término necesario de nuestras miras. $Y$ si nos aterra, ¿cómo adelantar un paso sin sentirnos febriles? El remedio del vulgo es no pensar en ella, mas ¿qué brutal estupidez puede producir tal ceguera?"

Sin embargo, los esfuerzos por ignorar a la muerte o negarla no conducen, precisamente, a un resultado positivo. Un tanatólogo experimentado, el Dr. John Hinton, nos dice al respecto lo siguiente: "Los esfuerzos por negar la muerte y la mortalidad no son totalmente eficaces, $y$, cuando fracasan, pueden incluso aumentar el sufrimiento". ${ }^{10}$ Coincidentemente, la Dra. Elizabeth KüblerRoss, que ha acumulado una valiosa experiencia en el campo de la tanatología, añadirá: "Esta tendencia a rehuir el enfrentamiento con la muerte acarrea un mal indudable. Los pacientes mortalmente enfermos sufren más cuando quienes los rodean no están dispuestos a participar de los problemas personales del muriente"."

Pero, ¿por qué no se afronta la muerte con tranquilidad? Hay muchas razones. Sin embargo, nosotros pensamos que, cualesquiera sean éstas, es posible superar nuestra explicable intranquilidad y temor apoyándonos en la filo-

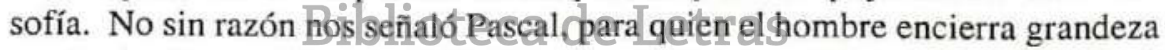
y miseria al mismo tiempo: "El pensamiento hace la, grandeza del hombre". ${ }^{12}$ Por eso, aun cuando el hombre es una caña, la más débil de la naturaleza, es una caña que piensa. Y es, precisamente, a los que han hecho de la tarea de pensar, de reflexionar, a quienes vamos a acudir en búsqueda de una respuesta a nuestras inquietudes.

Empezaremos con Martín Heidegger, conocido filósofo existencialista alemán. Para el maestro de Friburgo, el tema de la muerte, la preocupación frente a la muerte, no parece haber pasado de moda. Interesado como está en desarrollar una ontología, como es natural, no puede enfrentar el problema del ser sin evitar enfrentar, al mismo tiempo, el tema del acabamiento.

\footnotetext{
* Miguel de Montaigne, Ensayos, I. p. 50.

- Loc cit.

10 John Hinton, Op. cit., p. 20.

1 Elizabeth Kubler-Ross, Conferencias. Morir es de vital importancia, p. 21.

12 Blas Pascal, Pensamientos, I, p. 126.
} 
Afirma nuestro filósofo, que es necesario partir del reconocimiento de que el ser del hombre es, fundamentalmente, el ser-en-el-mundo. El hombre, que es el único ser capaz de interrogarse sobre sí mismo, constata que la existencia humana es un ser ahí (Das Dasein), un hallarse arrojado en el mundo. Pero toda existencia es temporalidad y esta temporalidad engendra una angustia. El hombre se angustia frente a la Nada, y en su búsqueda de una razón encuentra el secreto de su más honda condición: la de Ser para la muerte (Sein-zum-Tode). "El 'ser relativamente a la muerte' es en esencia angustia". ${ }^{13}$ Es desgarrador constatar que nos encontramos en medio de la muerte, en la muerte.

La muerte es la posibilidad más peculiar, irreferente e irrebasable; posibilidad que no se le depara al hombre en un momento tardío y ocasional, sino que desde el momento en que él existe es también ya yecto en esta posibilidad. En este sentido, podemos decir que, desde que nace, el hombre es ya suficientemente viejo como para vivir. ${ }^{14}$

En esto, Heidegger coincide con el filósofo Epicuro de la antigua Grecia (341-270 a. C.), quien decía al respecto: "Frente a las demás cosas es posible procurarse seguridad, pero frente a la muerte todos los hombres habitamos una ciudad sin murallas". ${ }^{15}$

La muerte es, además, nos sigue diciendo Heidegger, algo extremadamente singular y personal. ${ }^{6}$ Soy yo el que muere. Nadiespuede tomarle a otro su morir". ${ }^{17}$ Es imposible conocer la esencia de da muerte, a partir de la muerte de los demás. Por lo tanto, debemos pensar que la muerte es más que una cesación de vida, es un modo de vida.

Esto es lo que el hombre común no quiere ver y por eso inventa mil y una maneras de enfrentarlo. En las habladurías cotidianas él dirá de sí mismo: al fín y al cabo también uno morirá, pero por lo pronto no le toca a uno. Ya hemos mencionado, líneas arriba, que inclusive pensar en la muerte pasará públicamente por cobarde temor. Se llega, entonces, a una existencia inauténtica, puesto

\footnotetext{
${ }^{13}$ Martín Heidegger, El ser y el tiempo, p. 290.

${ }^{14}$ Ibfd.

${ }^{15}$ Epicuro, "Fragmentos y testimonios escogidos", en Carlos Garcfa Gual y Eduardo Acosta Méndez, Epicuro.

Ética. Texto bilingille, p. 147.

${ }^{10}$ Comparar con lo dicho por Pascal: "[...] se morirá uno solo" (PASCAL, Pensamientos, I, p. 162).

${ }^{17}$ Op. cit., p.262.
} 
que aquella aparente impavidez no es de buena fe pues se disimula en ella mucho pavor.

\section{Pero, entonces, ¿qué debemos hacer?}

Según Heidegger, lo aconsejable es revelar nuestra angustia y tratar de dominarla. El hecho de que aprendamos a reconocer la muerte como constitutiva de nuestro ser, sin huir de ella, nos permitirá tomar conciencia de nosotros mismos. Como el sabio que conoce y acepta la angustia, pero al mismo tiempo conoce la profundidad del ser y no una faz engañosa. Disfrutaremos, así, de una existencia auténtica, o sea, de una existencia que se haya vuelto a captar, a reconquistar. ${ }^{18}$

Hay, pues, que comprenderse muriendo. Tal es la conclusión que surge del análisis mismo de la condición humana, nos dirá Heidegger. ${ }^{19}$

En lo concerniente al problema desi existe o no una vida después de la muerte, el profesor alemán considerarấ que carece de sentido. No cabe ni siquiera preguntar por lo que será después de la muerte, ya que el análisis sólo puede mantenerse dentro de los límites del más acá. En consecuencia, no niega, pero tampoco afirma.

Quien sí se pronunciàdecididamente contrałla hipótesis de la inmortalidad es el filósofo Ludwig. Feuerbach. Éste se ubica decididamente al lado de la interpretación naturalista y rechaza tajantemente la creencia en la inmortalidad, que en su opinión únicamente es la expresión del deseo que siente el hombre de vivir aún después de la muerte.

\footnotetext{
${ }^{18}$ Algo similar nos dice Montaigne: «Meditar en la muerte por adelantado es meditar por adelantado en la libertas, y quien aprende a morir ha desaprendido a servir. No hay mal alguno en la vida para quien entiende gue la privación de la vida no es un mal. El saber morir nos libra de toda sujeción y restricción» (Op. cit.. p. 53).

${ }^{19}$ Volvemos a citar al autor de los Ensayos: "Por tanto recibamos y combatamos a la muerte a pie firme, y por comenzar quitändole su mayor ventaja contra nosotros tomemos camino opuesto al comin: privemos a la muerte de su rareza, practiquémosla, no tengamos en la mente cosa de más momento que ella, representémonosla en todos los instantes y con todas las cataduras, sea el resbalón de un caballo, una teja desprendida o una picadura de alfiler, y digamos: 'No importa que ello sea la muerte misma'. Fortalezcámonos, pues, y esforcémonos. Entre las fiestas y alegrias, recordemos esa nuestra condición y na nos dejemos llevar tanto por el placer que cesemos de pensar que, en muchas suertes, esa nuestra alegría desemboca en la muerte que de cerca la amenaza. Los egipcios, obrando asi, en medio de sus festines y en sus mejores banquetes, hacian sacar la calavera de un hombre, como advertencia a los convidados." (Ibid., p. 53).
} 
Pero, esta negación de la inmortalidad, ¿hará infeliz al hombre? No, responde nuestro filósofo. Dejemos que él nos explique las razones:

El deseo de la inmortalidad es contrario a la naturaleza humana, por lo cual la sola imaginación, abstrayendo de la realidad, pueda llegar a borrar los límites necesarios de nuestra individualidad. Estamos ligados a las condiciones de tiempo y de espacio, como a las leyes de la gravitación. Quien pretenda sobrepasar esos límites razona absurdamente, pues aun admitiendo la hipótesis de que los deseos de la imaginación pudiesen ser realizados, estaremos, indudablemente en contradicción con nuestro deseo principal de ser felices, puesto que lo que es contradictorio a nuestra naturaleza no podría convenirnos. ${ }^{20}$

Nuestro autor agregará que, por otra parte, si se le concediese al hombre el poder realizar este deseo, muy pronto se cansaría de vivir eternamente y experimentaría deseos de morir. En este punto, aunque por otras razones, coincide con Schopenhauer:

Si se le concediese al hombre una vida eterna, la rigidez inmutable de su carácter y los estrechos límites de su inteligencia le parecerían a la larga tan monótonos y le inspirarían un disgusto tan grande, que para verse libre de ellos concluiría por preferir la nada. ${ }^{21}$

Feuerbach afirma que la puccinelli. Convers. en en la inmortalidad suele verse robustecida frente a la constatación de una muerte prematura, con toda la carga de dolor y frustración que conlleva, pero, aun así:

Esas anomalías, aunque no raras, no nos dan el derecho de creer en la realidad de nuestros delirios, de suponer la existencia de un segundo mundo de los espíritus más anormal que éste. ${ }^{22}$

Por su parte, Epicuro, a quien ya hemos mencionado, nos aconseja: Eliminemos el temor a la muerte. Y, junto con él, el temor al dolor, el temor a la enfermedad, el temor a los dioses. Es éste el cuádruple remedio, el $\tau \varepsilon \tau \rho \alpha \varphi \alpha \rho \mu \alpha \kappa o v$

\footnotetext{
${ }^{20}$ Ludiwug Feuerbach, Esencia de la religión, pp. 147-148.

${ }^{21}$ Schopenhauer, op. cit, p. 79.

${ }^{22}$ Ludwig Feuerbach, op. cit., p. 148.
} 
que nos cura de la angustia y nos produce la ataraxia, la paz y la quietud del espíritu, la tranquilidad del sabio.

Como dice un autor, tal vez la salida sea aceptar que:

La superioridad de la razón es comprender, no sólo la necesidad de la muerte, sino también su utilidad, y aprobar la ley que nos condena a acabar. Por ahí el hombre se eleva por encima de los animales, que temen a la muerte sin conocerla, y cesa de temerla porque la conoce. $^{23}$

Como es natural, surge ahora la pregunta: ¿entonces, como ha de valorar el hombre la vida desde esta perspectiva de negación de la inmortalidad?

El resultado de nuestra crítica ha de ser, señala Feuerbach, que en el lugar de una vida eterna en el cielo, pongamos el porvenir histórico de la humanidad. Con el dogma de la vida futura, se apaga en el corazón todo interés por la vida real. Por lo tanto, hay que afirmar nuestra vida terrenal. En este sentido, la negación se convierte en afirmación. ${ }^{24}$

Sin embargo, esta existencia terrenal, la única a la que podemos racionalmente aspirar, no deja por ello de ser pasajera y limitada. En esas condiciones,

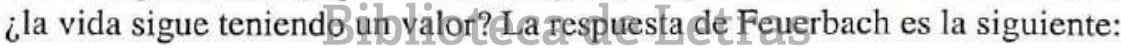

\section{"Jorge Puccinelli Converso»}

Las notas musicales, aunque suenan en el tiempo, están sin embargo, por su significación, fuera del tiempo y por encima de él. La sonata, compuesta de ellas, es también de breve duración, no se toca eternamente; pero ¿no es ella nada más que larga o corta? ¿Qué dirías, te pregunto, de quien durante la audición de la sonata, no escuchara sus notas, sino contase los minutos de su duración, tomando ésta como base de su juicio, y cuando todo el auditorio intentase expresar su admiración con palabras precisas, él no encontrase para caracterizarlo, sino esta frase; ha durado un cuarto de hora? Indudablemente la palabra loco te parecería demasiado suave para aplicarle a semejante hombre. ${ }^{25}$

\footnotetext{
${ }^{23}$ Bourdeau, op. cit., p. 356.

${ }^{24}$ Ibtd. pp. 149-150.

${ }^{25}$ Ibid., p. 151.
} 
La vida ha de valorarse, pues, no por su duración, sino por su contenido. Coincidentemente, Epicuro escribe al respecto: " $Y$ del mismo modo que [el sabio, anot. Nos., C.A.] del alimento no elige cada vez el más abundante sino el más agradable, así también del tiempo, no del más duradero sino el más agradable disfruta". ${ }^{26}$

Hemos mencionado a Epicuro y ahora vamos a ocuparnos de él. Se ha dicho que el objeto supremo de la doctrina de Epicuro es liberar al hombre del temor a la muerte. ${ }^{27}$ Efectivamente, al respecto escribió:

Acostúmbrate a pensar que la muerte nada es para nosotros, porque todo bien y todo mal residen en la sensación y la muerte es privación de los sentidos. Por lo cual el recto conocimiento de que la muerte nada es para nosotros hace dichosa la mortalidad de la vida, no porque añada una temporalidad infinita sino porque elimina el ansia de inmortalidad. Nada temible hay, en efecto, en el vivir para quien ha comprendido realmente que nada temible hay en el no vivir. ${ }^{28}$

Así, el temor a la muerte se sustenta en un terror pueril, pues suponemos que queda algo de nosotros después de ella, y ese algo es lo que nos inquieta y excita nuestra imaginación. Es una especie de terror supersticioso que soslaya el hecho indiscutible de que, siendo la muerte privación de los sentidos, nada podemos ya sentir unavez que ha sobrevenide $Y$ a agrega nuestro filósofo:

\section{"Jorge Puccinelli Converso»}

Así, pues, el más terrible de los males, la muerte, nada es para nosotros, porque cuando nosotros somos, la muerte no está presente y, cuando la muerte está presente, entonces ya no somos nosotros. ${ }^{29}$

Eliminemos, por consiguiente, el temor a la muerte. Y, junto con él, nos dirá Epicuro, el temor a la enfermedad, el temor al dolor y el temor a los dioses. Es éste el cuádruple remedio, el $\tau \varepsilon \tau \rho \alpha \varphi \alpha \rho \mu \alpha \kappa o v$, que nos cura de la angustia y nos produce la ataraxia, la paz y la quietud del espíritu, la tranquilidad del sabio.

\footnotetext{
${ }^{26}$ Epicuro, "Carta a Meneceo", en Carlos Garća Gual y Eduardo Acosta Mendez, Epicuro. Ética. Texto bilingue, p. 93.

${ }^{27} \mathrm{Cf}$. Guyau, La moral de Epicuro, p. 123.

${ }^{28}$ Epicuro, op. cit., p. 91.

${ }^{29} \mathrm{Ibid}$. p. 93.
} 
Tal es el consejo de nuestro filósofo. Y es con esta recomendación que habremos de llegar al final de nuestra exposición. Sacamos como conclusión que el hombre no tiene más alternativa que enfrentar con entereza su destino final:

La superioridad de la razón es comprender, no sólo la necesidad de la muerte, sino también su utilidad, y aprobar la ley que nos condena a acabar. Por ahí el hombre se eleva por encima de los animales, que temen a la muerte sin conocerla, y cesa de temerla porque la conoce. ${ }^{30}$

Y, de esta manera, aceptaremos con Marco Aurelio que: "Es preciso partir de la vida con resignación, como cae la aceituna madura, bendiciendo a la tierra, su nodriza, y dando gracias al árbol que la ha producido". ${ }^{31}$

Entonces, aun cuando el hombre, de todos los seres vivientes, es el único que sabe con certeza que ha de morir, tal vez sea parte de su grandeza aceptar su destino con honor.

BOURDEAU,Luis

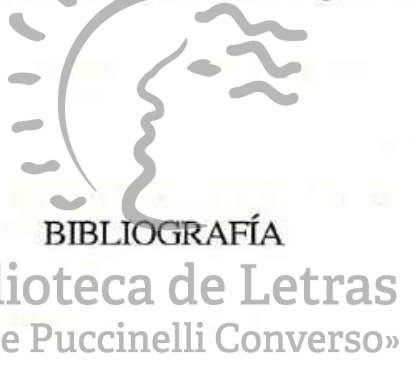

1902

El problema de la muerte. Madrid, Librería de Fernando Fe.

CEREJEIDO, Marcelino y BLANCK-CEREJEIDO, Fanny

1999

La muerte y sus ventajas. México, FCE.

FEUERBACH, Ludwig

1948 Esencia de la religión. Rosario, Editorial Rosario.

GARCÍA GUAL, Carlos y ACOSTA, Eduardo

1974 La génesis de una moral utilitaria. Epicuro. Ética. Texto bilingüe. Barcelona, Barral Editores.

30 Luis Bourdeau, op. cit., p. 356.

31 Ibid. p. 357. 
GUYAU, J.M.

1943

La moral de epicuro. Buenos Aires, Américalee.

HEIDEGGER, Martín

1983

El ser y el tiempo. México.

HINTON, John

1974

Experiencias sobre el morir. Barcelona, Editorial Ariel.

KÜBLER-ROSS, Elizabeth

1996

Conferencias. Morir es de vital importancia. Barcelona, Luciérnaga.

MONTAIGNE, Miguel de

1984

Ensayos. Buenos Aires, Hyspamérica. $3 \mathrm{t}$.

PASCAL, Blas

1973

Pensamientos. Madrid, Aguilar. 2 t.

SCHOPENHAUER, Arturo

El amor, las mujeres y la muerte.

SPINOZA, Benedicto

1980

Etica. Madrid, Editora Nacional 